\title{
ПЕРФОРМАТИВНЫЙ ПОВОРОТ В ПОСТСОВЕТСКОЙ КУЛЬТУРЕ
}

\author{
PERFORMATIVE TURN IN POST-SOVIET CULTURE
}

\author{
YAROSLAV POLISHCHUK
}

\begin{abstract}
AвSTRACT. The author of the article considers the elements of performance in the literary works of the post-Soviet period. His attention is focused on three East Slavic nations, whose literatures belonged to the area of "Soviet literature" for a long time. It is noted that the implementation of the elements of performance into the culture confirms the radical renewal of literary discourse and creation of new national narratives.

Keywords: performance, literature, writer, text, game, meaning

Yaroslav Polishchuk, Uniwersyet im. Adama Mickiewicza w Poznaniu, Poznań - Polska, yaropk@gmail.com
\end{abstract}

ORCID ID: 0000-0001-9081-7900

Перформативные практики в современной литературе и искусстве привлекают внимание многих исследователей. На Западе они вписываются в формулу пост-постмодернизма, то есть эстетических поисков, предпринимаемых на волне упадка постмодернизма и утраты авторитета его главных идей. Иная ситуация в странах Центральной и Восточной Европы, где опыт постмодернизма обрел относительно скромную (и преимущественно фрагментарную) репрезентацию. Связано это с тем, что политические и экономические факторы, непосредственно влияющие на состояние общества, не вызвали такой широкой востребованности постмодернистского нарратива, как это случилось на Западе. Соответственно переход к новому этапу тоже сохраняет свою устойчивую специфику.

Перформанс в наше время обретает универсальный характер, так как его присутствие наблюдается в разных отраслях искусства и культуры. Это стало следствием стремительного развития массовой культуры в современном мире, а также процессов глобализации и бума масс-медиа, которые способствуют молниеносному распространению новых культурных практик. Перформативный поворот в культуре является характерной реакцией на новую конфигурацию искусства в контексте нашей эпохи: оно не просто аккумулирует художественную ценность, как раньше, но также представляет ее, пользуясь современными средствами 
выражения. Взаимное сближение искусства и действительности приводит к поиску новых эстетических средств, а также новых - зачастую гибридных - форм и жанров художественного творчества.

В наше время категории перформанса обрели новые смыслы, они охватили разные сферы жизни и культуры. Человек в современном мире как никогда тесно связан с перформативными практиками. Они, как утверждает известный теоретик и практик перформативного искусства Ричард Шехнер, окружают нас в повседневном быту. Существует несколько значений понятия perform (демонстрация). Во-первых, когда мы делаем что-либо, чтобы достичь успеха, показательно. Во-вторых, это значение охватывает различные явления в искусстве, связанные с публичным действием, - шоу, танец, концерт, ритуал. В-третьих, в обыденной жизни человек тоже прибегает к подобной практике, ибо склонен к „проигрыванию” определенных действий, имея в виду наблюдателей и соучастников, для которых это будет интересно или важно [Schechner, Brady 2006: 28]. Таким образом, перформативные практики занимают очень важное место в жизни современного человека. А стремительное развитие масс-медиа только усугубляет эту тенденцию.

Перфомативное восприятие мира имеет свои особенности. Оно „маркирует идентичность, граничное время, изменяет и украшает тело, а также рассказывает историю", как замечает Шехнер [Schechner, Brady 2006: 28]. В современных условиях мы невольно нацелены на активное восприятие искусства. Недостаточно производить и предлагать „чистое" искусство, его следует также представлять, показывать, „проигрывать”. В контексте доминирующей в мире массовой культуры это становится всеобщей нормой.

Акцентирование на перформативной эстетике проявилось также в исследованиях литературы. Оно связано с современными попытками пересмотра отношений художественного текста и внетекстовой реальности. Если раньше литературоведы ориентировались главным образом на текст, подыскивая ключи к его пониманию, то сегодня, в эпоху упадка теоретической мысли, они обращают больше внимания на связи текста с действительностью, что создает возможности живого контакта и преобразуется в своеобразную игру, обеспечивая тем самым поле перформативного влияния искусства.

Такое смещение теоретических акцентов является весьма замечательным. Жак Деррида размышлял об этом в последний период своей жизни, уточняя и развивая идеи деконструктивизма и перформатики. В книге life.after.theory (2002) ученый признавал, что опыт, наряду с событием, имел для него всегда наивысшую ценность. Отвечая на вопрос, что последует после теории, от утверждал, что остается текст, но уточнял 
(ввиду того, что его слова нередко понимали неточно и искажали смысл сказанного), что имеет в виду становление и развитие отношений между текстом и миром. Именно этот аспект актуализирует Анна Бужиньска:

Podkreślił więc, że zarówno teraz, jak i wcześniej, szło mu przede wszystkim o wyrwanie się z zamkniętego kręgu języka oraz z hermeneutycznego 'kokonu', zredukowanego do wewnętrznej 'gry znaczących'. Czyli o otwarcie się na wszystko to, co - tak jak 'zdarzenie się doświadczenia' - 'przychodzi' [2013: 520].

Перформативный поворот в исследованиях литературы отражает динамику в познании способов интерпретации искусства и его влияния на человека. В специальных трудах этот процесс характеризуется как отказ от дихотомического восприятия мира и привычных оппозиций типа искусство/действительность, объект/субъект, тело/дух, животное/человек, значащее/значимое и под. [Fischer-Lichte 2008: 271]. Сегодня развитие идеи перформанса относительно художественной литературы занимает умы многих западных ученых. Оно представлено в работах ряда известных исследователей, например в трудах Дерека Эттриджа [Attridge 2007] и Джона Хиллиса Миллера [Miller 1991]. Рауль Эшельман вообще предполагает, что наступила эпоха перформатизма, которая пришла на смену постмодернизму [Eshelman 2012: 245], поэтому исследование перформативных практик ученый считает одной из первостепенных задач современной науки. Западный научный дискурс, безусловно, все глубже проникает в сознание восточноевропейских обществ, обуславливая в нем серьезные сдвиги и открывая новое поле для рефлексии. Тем не менее в этом пространстве устойчиво проявляется определенная специфика в создании и восприятии перформативных практик. Эта специфика вызвана своеобразностью ситуации, когда осуществляется поиск новых эстетических ключей, нового языка искусства - после затяжного кризиса советской эпохи.

В постсоветской литературе процесс радикальной трансформации сопровождался как динамическим развитием, так и моментами застоя и неопределенности. Этот процесс кажется замечательным в том отношении, что он отражает непростой путь от идеологически ангажированного искусства к освобождению от жестких ограничений и „смене вех”. Учитывая широкий контекст проблемы, мы ограничимся в этой статье наблюдениями над отдельными элементами перформативной эстетики, появляющимися в постсоветской литературе и отражающими ее постепенную, но неуклонную эволюцию в сторону современной игровой культуры. При этом обратимся к примерам из русской, белорусской и украинской литератур. Предложенный исследовательский аспект интересен тем, что позволяет определить не только сходство указанных 
литератур (оно несомненно и подтверждается длительной традицией их тесного соприкосновения в прошлом), но также наблюдать заметную тенденцию к охлаждению их взаимоотношений в последнее время, в новой геополитической конфигурации, которая сложилась после краха Советского Союза. В конце XX и начале XXI века каждая из восточнославянских литератур претерпела существенные изменения, приведшие к их переориентации в процессе современных общественно-культурных преобразований Восточной Европы. Впрочем, отдельные наблюдения и оценки, приведенные в этой статье, не исчерпывают богатства материала, а только маркируют его определенным образом.

Сравнение ситуации в отдельных странах показывает, что вместе с общими тенденциями налицо также заметные отличия, которые тесно связаны со спецификой трансформационных процессов, затронувших за последние 25 лет практически все сферы общественной жизни постсоветских стран. Такие отличия заметны в судьбах авторов и целых поколений писателей как созидателей литературного корпуса, а также в ситуации на книжном рынке и в литературной жизни той или иной страны. И естественно, они заметны также в развитии новых литературных течений, раньше вообще не присутствовавших или представленных лишь маргинально (постмодерн), а также в перестановке тематических приоритетов, типов героев и т.п. [Matejko 2017: 111].

Перформативная культура в постсоветском обществе не обрела такой популярности, так на Западе. Она преимущественно выступает как локальное явление, в ограниченном пространстве. К тому же, определенные ограничения касаются также функциональности перформанса. Причины этого коренятся в недавнем прошлом, в котором искусство поддавалось жесткой регламентации. Оно было отраслью культурного производства и фактически исключало (или существенно ограничивало) свободу самовыражения художника. Как указывал Борис Гройс, вся советская жизнь была произведением искусства, в то время как инновационный обмен между искусством и жизнью оказался невозможным. Искусство, вынужденное находиться в состоянии стагнации, отмечалось „вечным возвращение прошлого” [Гройс 1993: 6]. Отказ от этой практики дается нелегко и требует длительного времени.

Преодоление советского дискурса предопределяет, между прочим, потребность переформатирования литературы как искусства живого, гуманистического, очеловеченного, с присущей человеку гаммой чувств и эмоций. В прошлом „советской литературы” остался ее холодный коллективистский пафос, который утратил реальный контакт с читателем и обусловил эффект отчуждения искусства. Игровой элемент в советском искусстве был, по существу, минимизирован, он претил самому духу подцензурного творчества. Характеризуя литературную традицию 
XX века, Михаил Эпштейн указывал, что в ней доминировала „серьёзность”, хотя в границах этого понятия можно наблюдать определенные колебания:

При всей ценностной несоизмеримости высокого модернизма и соцреализма, оба направления представляют собой эстетику серьёзного эклектизма, которая и в СССР, и на Западе опосредовала переход от раннего (авангардного) модернизма к постмодернизму. Разумеется, сама серьёзность может выступать в разных видах пафоса: героико-оптимистического или трагико-пессимистического. Героика соцреализма основана на ценностях всеобъемлющего коллективизма; трагизм высокого модернизма - на ценности индивидуального, которое в своих попытках приобщиться к универсальному, в том числе социальному, осознаёт неизбежность своего глубокого экзистенционального отчуждения [Эпштейн 2005: 96].

Яркая вспышка постсоветского перформанса связана с периодом упадка СССР и рождения новых независимых государств, то есть в 19891991 гг., когда на смену устаревшим формам советской культуры приходит пристрастие к эксперименту и новаторству, выраженное, в частности, в творчестве молодых авторов. Дух этого переходного периода, несмотря на его кратковременность, оказался очень сильным и креативным, он выполнял свою созидательную функцию также в последующие годы. Если воспользоваться термином Кенни Падрика, можно назвать его „революционным карнавалом" [Padraic 2002], правда, с некоторыми предостережениями. Американский ученый писал об атмосфере общественно-культурного перелома этого периода, сосредоточившись на странах Центральной Европы, освободившихся от коммунистической власти, - Польше, Чехии и др. Он считает, что именно перформативные практики сыграли ключевую роль в ходе мирной трансформации общества, так как они обрели массовый характер и способствовали разложению старой системы власти, но при этом сохраняли определенный баланс сил и не гальванизировали больших конфликтов, способных вызвать опасную турбулентность в целом обществе. В этом отношении заслуги перформанса не вызывают сомнения: вызревая поначалу в сфере искусства и культуры, он быстро перешел условные границы и оказал влияние на политические структуры общества, ускоряя тем самым их реформирование.

Развитие этого процесса Кенни Падрик выразил в целом верно: от „социалистического сюрреализма" 80-х гг. до постепенного закрепления в культуре легких игровых форм и жанров, а потом - до всеобщего „революционного хепенинга", который охватил весь регион [Padraic 2005: 192-196]. Тем не менее в своем исследовании перформативных практик в быстро изменяющихся обществах Центрально-Восточной Евро- 
пы, а также их влияния на эффективную смену политических режимов Падрик почти не затронул Советский Союз. Он объясняет это тем, что страна распалась не вследствие массового протестного движения, а наоборот, по причине внутреннего кризиса режима и его неспособности удержать власть. Впрочем, ученый все-таки приводит некоторые примеры из общественно-культурной жизни Украины, анализируя деятельность „Общества Льва” во Львове [Padraic 2005: 151-158]. Таким образом, он косвенно признает, что перформативные явления были присущи также советскому пространству, хотя именно в означенное исследователем время они ярко не проявились. Развивая эту идею, можно предположить, что вспышка перформанса все-таки имела место также на закате СССР, с той разницей, что, в отличие от центральноевропейских стран, она „растянулась” во времени, к тому же не была такой эффектной, как в центре Европы, по ряду причин.

Стоит заметить, что возвращение перформанса в постсоветском пространстве сопровождалось условной реконструкцией его исторической традиции. Не случайно в 80-е годы XX столетия громкий резонанс (причем не только в академической среде) обрели исследования Михаила Бахтина, в частности его теория средневекового карнавала. В своем известном труде Творчество Франсуа Рабле и народная культура Средневековъя и Ренессанса (1965) российский ученый показал роль карнавала в культуре старого времени, однако отдельные его тезисы выразительно перекликаются также с оценками современности (следует учитывать фактор цензуры, так как Бахтин работал в условиях жесткой идеологической регламентации научных исследований в СССР). Если предположить, что теория Бахтина имеет универсальный характер, то ее ведущие идеи вполне могут накладываться на реалии новейшего времени. Так, ученый воспринимал карнавал как рекреационное время, когда „мир встает с ног на голову”, а люди обретают возможность „перевести дух". В бахтинской интерпретации карнавала акцентируется коллективный характер этого явления, в контексте которого индивид чувствует себя „членом массового народного тела" [Бахтин 2010: 273]. Неизбежным также является повторяемость определенных действий, например парадов и походов. Карнавальный смех, таким образом, концентрирует определенные эмоции в определенном времени, прибегая при этом к формам массовой репрезентации. Он воплощает момент свободы в обществе, которое в целом не может считаться свободным. Карнавал предлагает людям временное отступление от нормы: игнорируя ее, человек забывает о бремени настоящего, абстрагируется от него.

Ситуация перехода, характеризующая период распада СССР, во многом предопределяла качество карнавала. Ослабление режима по- 
литического давления в 80-е годы привело к стремительному развитию различных общественно-культурных инициатив. В отличие от Центральной Европы, в республиках бывшего Советского Союза деконструкция власти не обрела такой решительности и такой массовой поддержки. К тому же позиция власти, опирающейся на консервативные силовые структуры, была еще довольно крепкая. Это объясняет специфику восточноевропейского перформанса, а именно: а) его несинхронность с центральноевропейским карнавалом конца 80-х; б) определенную растянутость во времени; б) „точечный”, фрагментарный характер.

В России самые заметные формы перформанса конща 80-х и начала 90-х связаны с презентацией визуального искусства. Неслучайно на смену периоду „новой волны”, разрушающему соцреалистическую эстетику в застойные 80-е годы (Владислав Мамышев-Монро, Сергей Курехин, группа „Популярная механика” и др.) в начале новой эпохи приходит движение акционистов, т.е. художников, стремящихся к „прямому действию", апробирующих новые формы взаимодействия с культурным пространством. Заметим, что эти мастера принципиально выходят за границы закрытых площадок. Их интересует прежде всего пространство большого города, поэтому они устраивают свои акции на площадях и улицах (Анатолий Осмоловский, Александр Бренер, Авдей Тер-Оганян, Олег Кулик). Художники первыми начали рассматривать соцреализм не в качестве идеологического конструкта, как он был задуман, а в качестве своеобразного текста культуры. Они обнаружили, что этот текст составлен из набора стереотипов и штампов, регламентирующих не только искусство, но и всю жизнь в Советском Союзе, и попытались использовать соцреалистические штампы как строительный материал для создания нового стиля искусства.

В литературе подобная тенденция тоже заметна, хотя ее труднее отслеживать. Постепенное разложение советского дискурса привело, с одной стороны к соц-арту и концептуализму, что проявилось в творчестве „лианозовской группы” поэтов 1980-х гг. [Лейдерман, Липовецкий 2006: 427]. Замечательно, что из этой „школы” вырос Владимир Сорокин, один из самых выдающихся представителей современной русской прозы, блестящий стилист. С другой стороны, ослабление цензуры способствовало становлению кружка поэтов-иронистов, пародирующих стиль соцреализма и культивирующих разного рода текстуальные игры с традицией (Игорь Иртеньев, Юрий Арабов, Тимур Кибиров, Нина Искренко, Виктор Коркия). Писатели ощутили острую потребность создания иронической дистанции от прошлого, что являлось предпосылкой его будущего переосмысления [Дашкова 1998]. 
Ориентация на массового потребителя привела к внедрению перформативных элементов в многочисленные литературные тексты: отсюда появляется обсценная лексика, субкультурная среда, „параллельные миры” и „черная" эстетика (Владимир Маканин, Ирина Денежкина, Виктор Пелевин, Виктор Ерофеев и др.) [Эпштейн 2005; Журбина 1993]. Один из мастеров современного перформанса в новейшей русской литературе, Виктор Пелевин предложил очень удачное сочетание формата массовой культуры и виртуальной действительности, что обеспечило большой успех его романов Омон Рa (1992), Жизнь насекомых (1993), Чапаев и Пустота (1996), Generation П (1999). Внимание читателей привлекли необычные воображаемые сюжеты Пелевина, но не менее важно, что они развертываются на фоне хорошо узнаваемых реалий советской и постсоветской действительности. Параллельный мир, созданный творческим воображением писателя, хорошо отражает кризис безвременья. Образ Пустоты из самого известного его романа вырастает до глобальной метафоры. Этот образ олицетворяет не только опустошенность конкретного места и времени (подразумеваем советское культурное пространство, потерпевшее тотальное крушение), но и ментальную, экзистенциальную, даже метафизическую пустоту, образовавшуюся на почве разочарования в советском дискурсе [Корнеев 1997]. Таким образом, автору удалось воплотить наиболее оригинальные черты русского постмодернизма [Курицын 2000: 175].

Эффект карнавала в конце 80-х и первой половине 90-х гг. XX столетия был весьма ощутим в литературной жизни Украины. Его самым известным проявлением является деятельность основанной в 1985 году группы молодых поэтов „Бу-Ба-Бу”1 в составе Юрия Андруховича, Виктора Неборака и Александра Ирванца. И сами „бубабисты”, и их подражатели, а также последователи (группы „ЛуГоСад”, ,"Пропала грамота”, „Новая дегенерация") культивировали новый способ общения с читателем. Они устраивали литературные вечера и хепенинги, во время которых не только читали собственные произведения, но и смело импровизировали. Это приучало публику к упразднению барьеров между автором и читателем, а также к упразднению внутренних барьеров восприятия поэзии. Художественный образ мира, представленный в первых романах Юрия Андруховича Рекреации (1992), Московиада (1993), Перверсия (1996), вполне напоминает ситуацию карнавала с его неотъем-

${ }^{1}$ В названии этой группы задекларированы эстетические приоритеты молодых авторов: бурлеск, балаган, буффонада. Ориентация на смеховую культуру (не без влияния вышеупомянутой теории Михаила Бахтина) предполагала не только успешную деконструкцию советского нарратива, но и формирование сознания нового человека, освобожденного от „казенного” наследия советской эпохи. 
лемыми атрибутами - масками и мистификациями. Так, герои первого из указанных романов „проигрывают” карнавальное шествие, будучи участниками массового народного праздника в условиях стремительного возрождения национально-культурной идентичности украинцев. При этом авторская позиция оказывается амбивалентной: он насмехается над простодушием и наивностью участников праздника, но в то же время не отрицает серьезный смысл, заложенный в карнавальном действе. В романе Московиада авторская ирония становится более жесткой, а картины Москвы во время общественного хаоса и упадка конца 80-х годов приобретают гротескно-карикатурную окраску. Как заметил американский исследователь Марк Андрейчик, в литературе переходного времени сочетались тенденции эйфории, хаоса и общности [Андрейчик 2014: 177], определяя собой новое состояние литературного творчества.

В яркой форме перформативная эстетика была выражена в организации двух фестивалей альтернативной культуры и нетрадиционных жанров искусства „Вывих” (1990, 1992), которые с большим успехом проходили во Львове. Эти фестивали раскрыли большой созидательный потенциал перформанса, воплотив в жизнь массовый интерес к радикальным изменениям в сфере культуры, прежде всего в молодежной (альтернативной) литературе. Они показали, что дух карнавала способен преобразиться в рождение новой эстетики, освобожденной от стереотипов прошлого и открытой к вызовам будущего. Именно такую атмосферу в годы развала СССР отмечал во Львове несколько раньше Кенни Падрик на примере культурных инициатив „Общества Льва” [Padraic 2005: 154-158].

В белорусской литературе переломного периода подобные постколониальные тенденции проявились с не меньшей выразительностью, хотя позже были приостановлены и заморожены по политическим мотивам. С появлением нового поколения писателей пришло понимание радикального разрыва с советской литературой [Кісліцына 2014]. Создание творческих объединений, культивирующих авангардистское искусство, указывает на разрыв с советским наследием и переориентацию в сторону западной культуры. Молодые авторы стремились ",сделать бум" в отечественной культуре, освобождая ее от закостенелого наследия советской эпохи. И если вначале деятельность группы альтернативного творчества „Тутэйшыя” (1986-1989) не отмечалась громкими публичными акциями [Кавалёв 2013: 7], то уже в созданном позже творческом объединении „Бум-Бам-Літ” (1995) перформативные практики были налицо. Впрочем, характерная тенденция к публичной презентации произведений с привлечением элементов перформанса проявилась уже в творческой активности „Тутэйшых": они охотно 
выступали на митингах и литературных вечерах, устраивали традиционные дни памяти („Дзяды”). Продолжение такой практики можно наблюдать в деятельности „Таварыства вольных литаратараў”, основанном в 1993 году, а также упомянутого выше „Бум-Бам-Літа”. История белорусской альтернативной литературы 80-90-х гг. XX в. хорошо иллюстрирует тезис о стремительном возрастании роли перформативной составляющей в постсоветской культуре.

Удачным примером белорусского перформанса можно считать то, как благодаря современной литературе обрел новый, более привлекательный облик город Минск. Раньше он ассоциировался с серым и однообразным „совком” и вызывал депрессивные настроения, казался неприятным и мертвым местом. Зато в текстах молодых авторов столица молодой страны представлена уже в совершенно ином ракурсе: как место встречи и „тусовки”, противопоставленное дискурсу власти и олицетворяющее освобождение от провинциальности и маргинальности в прошлом [Belarus 2010: 37-39]. Примером преодоления негативного стереотипа может служить эссе Артура Клинова Минск. Путеводитель по Городу Солнияа (2013). В известном романе Игоря Бобкова Минутка. Три истории (2013) воспроизводится своеобразная, эйфорическая и меланхолическая одновременно, атмосфера прощания с советским прошлым, отраженная на примере минской молодежи периода политической трансформации конца 80-х - начала 90-х гг. XX века.

В XXI веке игровые формы литературного творчества приобретают особую популярность. С одной стороны, они апеллируют к западным аналогам, обладающим огромной популярностью и задающим определенный формат в мировой культуре, особенно в контексте стремительного развития цифровых технологий, позволяющих создавать всё новые и новые увлекательное игры. С другой же стороны, попытки вписывания писателями в контекст игры отечественной истории, культурной традиции, национальной ментальности приводят к неожиданным результатам: перформанс обретает новые смыслы и коннотации. Эту мысль можно проиллюстрировать хотя бы на примере жанра романа-антиутопии, который в последнее время охватывает довольно важный сегмент русской литературы. Романы Виктора Пелевина Священная книга оборотня (2005), Ольги Славниковой 2017 (2006), Владимира Сорокина Голубое сало (1999) и День опричника (2008), Дмитрия Быкова Ж/Д (2016) отмечены многозначностью перформативного опыта, выходящего далеко за пределы развлекательного эффекта. Хотя сами авторы воспринимали их как чистый вымысел и рискованную игру с запретными составляющими, политическая действительность в стране сделала те или иные акценты очень актуальными, поэтому они воспринимаются читателями как 
мрачное пророчество, как предостережение фатального развития событий в современной и будущей России.

В последнее время в России (и также в русскоязычном культурном пространстве) постепенно утрачивается интерес к живой современности, что непосредственно сказалось на сужении поля перформативных опытов. Литературоведы говорят о преобладании культа прошлого и будущего в современном творчестве, что нельзя не связывать с консервативной политикой государства, направленной на реставрацию бывшей империи и ее культурного наследия. Так или иначе, это сказывается на кризисе эпических форм, в частности романа. Марк Липовецкий определяет это явление как „страх настоящего”, когда писатели отдают предпочтение либо осмыслению опыта прошлого, причем с заметными чертами ностальгии, либо фантастическому моделированию будущего. С другой же стороны, в литературе все равно присутствует перформативное начало: просто в настоящих условиях поле его применения несколько изменилось. Как указывает критик, оно переместилось к другим литературным жанрам. Таким образом, наличие перформативных практик можем наблюдать в социально ангажированной поэзии или актуальной драматургии. Так,

проникнув на Фейсбук, поэзия, даже самая сложная и интимная, приобрела совершенно новые качества - она стала перформансом по умолчанию. А что такое перформативность, если не выход в неготовую современность? Аналогично и драматургия, вернее, та ее часть, что относится к кругу „новой драмы”, с одной стороны, тяготеет к современному искусству - экспериментальный „постдраматический” театр, включая и докудраму, радикально размывает границу между сценой и перформансом. А с другой стороны, „новая драма” прямиком ведет к кинематографу „новых тихих” - „тихих” не потому, что им неведом социальный протест (как говаривали до „Левиафана”), а именно потому, что режиссеры этого круга удивительным образом переводят на язык визуальных образов литературу и литературность. Не зря один из лучших фильмов последних лет так и называется - „Рассказы” и, собственно, посвящен отношениям современности с литературностью [Липовецкий 2017].

Преодоление существующего кризиса в развитии художественной литературы постсоветского культурного круга пока что не выглядит оптимистично и вызывает много вопросов. Конечно, в настоящей ситуации следует рассматривать много факторов: вовлеченность литературы в государственную идеологию, незавершенная модернизация, перешедшая в консервативный откат к советскому прошлому, бум новых масс-медиа и массовой (потребительской) культуры, утрата интереса к чтению и т.п. Современная русская литература с переменным успехом пытается преодолеть состояние кризиса, вызванное утратой великого нарратива, а так- 
же - в значительной мере - и разрывом с великой традицией, который оказался очень болезненным. С начала нового столетия она

осознает кризисность своего существования, обнаруживает множественность путей тупикового развития, дробится и капсулируется... Литературные явления становятся предметом одноразового употребления - и закрытых интерпретаций. Общенациональные критерии подвергаются сомнению. Идет борьба между каноническим и неканоническим подходом к литературе: побеждают деиерархизация, эгалитаризм и релятивизм. [...] Литература обогащает свои возможности за счет привлечения резервов маргинальных и внелитературных явлений. Образуются полузамкнутые центры литературной жизни в виде „тусовок" [Иванова 2007: 41].

Ограниченная востребованность перформативных практик, несмотря на ее объяснимость прошлым опытом литературы, сегодня кажется сдерживающим фактором: она гальванизирует настоящее состояние неопределённости и кризиса, а также сдерживает развитие новых форм и блокирует свободное экспериментирование в творчестве. Необходимым условием современного перформанса является состояние свободы, которым обладает как мастер, так и его публика. Это кажется аксиоматичным, но все же в контексте постсоветских государств, где такая свобода имеет свои ограничения, довольно ощутимые, следует обращать внимание на „герметизацию” перформативных средств искусства. И тот, кто прибегает к перформансу, и тот, кто его воспринимает или интерпретирует, все же пытается каким-то образом преодолеть жесткое разграничение искусства и жизни. Как замечает Ричард Шехнер, тот, кто занимается перформансом, не исследует ни одного продукта искусства или культуры обосабленно (будь то литературный текст, произведение архитектуры, музыки и т. д.). Его интересует не отдельный продукт в его самости, а наоборот, элемент „постоянной игры связей и обмена”, что, собственно, и представляет собой „перформанс” [Schechner 2006: 40]. Именно произвольность таких взаимосвязей в постсоветской литературе не всегда возможна: если ее удается достигнуть на уровне текста, то его рецепция (в частности, восприятие и реакция в публичной сфере) оставляет желать лучшего.

Перформанс является парадигмой экспериментальной культуры. Не случайно он связан, главным образом, с самовыражением молодого поколения, а также сопряжен с авангардистскими поисками в сфере искусства. Важно разглядеть конструктивную роль перформанса в построении нового национального нарратива - именно эта черта привлекает сегодня особое внимание в развитии русской, украинской и белорусской литератур в постсоветское время. Хотя перформанс обычно позиционируется как разновидность легкой, игровой культуры, 
с ярко маркированным развлекательным элементом, нужно отметить, что перформативное искусство является также выразителем серьезных смыслов, имеющих нередко ключевое значение в современном мире. Поэтому нельзя недооценивать перформативные практики, в частности в представленные в данной статье, когда речь идет о литературе в состоянии кризиса и перелома, а также поиска новой парадигмы развития.

\section{Библиография}

Андрейчик М. 2014. Інтелектуал як герой украӥнської прози 90-х років, пер. 3 англ. I. Андрущенка, Львів: ЛА Піраміда.

Бахтин М. 2010. Творчество Франсуа Рабле и народная культура Средневековья и Ренессанса,

[в:] М. Бахтин, Собрание сочинений в 7-ми томах, т. 4 (2), Москва: Русские словари. Гройс Б. 1993. Утопия и обмен (Стиль Сталин - О новом - Статьи), Москва: Знак.

Дашкова Т. 1998. Постмодернистский мета-миф в русской поэзии „новой волны”, [в:] Л. Кисельовфа (ред.), Ритуально-міфологічний підхід до інтерпретації тексту, Київ: I3MH.

Журбина Е. С. 1993. Посттоталитарная культура: „все дозболено” или „ничего не гарантировано"?, „Вопросы философии", № 3.

Иванова Н. 2007. Ускользающая современность. Русская литература XX-XXI веков: от "внекомплектной к постсоветской, а теперь и всемирной, „Вопросы литературы”, № 3.

Кавалёу̃ С. 2013. Пачвара у рэліктавым лесе. Літаратура. Тэатр. Крытыка, Мінск: Мастацкая літаратура.

Кісліцына Г. 2014. Сучбеллит и чароўны пендзель, электронный ресурс: http:/ /n-europe.eu/columns/2014/01/14/suchbellit_i_charouny_pendzel (доступ 19.11.2017).

Кобрин К., Липовецкий М., Страх настоящего. Русская литература сегодня. Кирилл Кобрин и Марк Липовецкий: переписка из двух углов, электронный ресурс: https:/ / www.colta.ru/articles/literature/15386 (доступ 19.11.2017).

Корнеев С. 1997. Столкновение пустот: может ии постмодернизм быть русским и классическим?, „Независимое литературное обозрение”, № 28.

Курицын В. 2000. Русский литературный постмодернизм, Москва: ОГИ.

Лейдерман Н., Липовецкий М. 2006. Современная русская литература, т. 2, Москва: Высшая школа.

Эпштейн М. 2005. Постмодерн в русской ^итературе, Москва: Высшая школа.

Attridge D. 2007. Jednostkowość literatury, przeł. P. Mościcki, Kraków: Universitas. Burzyńska A. 2013. Dekonstrukcja, polityka i performatyka, Kraków: Universitas.

Eshelman R. 2012. Performatyzm albo koniec postmodernizmu ("American Beauty"), przeł. K. Hoffmann i W. Szwabs, „Przestrzenie Teorii”, т. 17.

Fischer-Lichte E. 2008. Estetyka performatywności, przeł M. Borowski, M. Sugiera, Kraków: Księgarnia Akademicka.

Janka К. (ред.) 2010. Belarus inside out. Беларусь знутры і збонку, Berlin-Minsk: Rejs e.V. 
Matejko L'. 2017. Oт „советской митературы” к национальным митературам на постсоветском пространстве: случаи Украины, Беларуси и Азербайджана, [в:] L'. Matejko (ред.), Literature and Social Change: A Voyage Through the History of Slavic Studies, Bratislava: Porta Danubiana, Comenius University.

Miller J. H. 1991. The Ethics of Reading, [в:] J. H. Miller, Theory Now and Then, Durham: Duke University Press.

Padraic K. 2002. A Carnival of Revolution: Central Europe 1989, Princeton: Princeton University Press.

Padraic K. 2005. Rewolucyjny karnawał. Europa Środkowa. 1989, przeł. P. Szymor, Wrocław: Princeton University Press.

Schechner R. 2006. Performatyka: wstęp, przeł T. Kulikowski, Wrocław: Ośrodek Badań Twórczości Jerzego Grotowskiego i Poszukiwań Teatralno-Kulturowych.

Schechner R., Brady S. 2006. Performance Studies: An Introduction, London-New York: Taylor \& Francis Ltd. 